\title{
Optimism vs. Realism with Regard to Educational Technologies
}

\author{
J. Michael Spector ${ }^{1}$
}

Published online: 27 June 2017

(C) Association for Educational Communications \& Technology 2017

These comments were written following a discussion with five leaders from Beijing National Day School (BNDS; see http:// bjshiyi.org.cn/ and also https://en.wikipedia.org/wiki/Beijing National_Day_School) with leaders in the College of Information at the University of North Texas (COI; see http:// coi.unt.edu/). BNDS is a highly regarded and innovative residential middle and high school established in 1952, with more than 5000 students living on campus and attending classes. It is a public school with open admission at the junior high school level and highly competitive admission at the high school level. The curriculum is focused on experiential learning in nearly every subject area with students collaborating on the design, creation, refinement, and marketing of a variety of things (ranging from clothing products to engineered objects) with proceeds coming back to BNDS.

The BNDS group was visiting highly innovative high schools in the USA to gain ideas for future developments at BNDS and stopped at the COI as two faculty there had visited BNDS a few months previously. During the visit, the BNDS principal asked COI faculty what the impact of innovations in technology had been on learning and instruction. There ensued a discussion based on a response I made that was not what they had expected to hear. I claimed that two major mistakes have occurred in the USA with regard to educational technology innovations:

(1) those advocating for a technology often overpromised what outcomes would occur, and

J. Michael Spector

Mike.Spector@unt.edu

1 Department of Learning Technologies, University of North Texas, Denton, TX, USA
(2) when a new technology was actually implemented, it was done with minimal changes to curricula and instructional approaches, which I called a replacement strategy.

I added that too little support had been provided to teachers who became responsible making effective use of the technology in schools. Another faculty member then cited some significant results from various National Science Foundation projects with which he has been involved. There ensured a spirited dialogue about the impact of technology innovations on learning and instruction, which was the primary focus of the BNDS visit to the USA. Parts of that dialogue are reflected below.

One can be optimistic about the potential to use technology to improve learning and instruction. Many in this room and elsewhere are justifiably optimistic in spite of past shortfalls. However, there is very little evidence of large-scale (e.g., nationwide) sustained improvement in learning and instruction due to the various uses of technologies in recent and not so recent years in the USA. There have been two funded educational projects that managed to have large-scale and sustained impact over the years (perhaps there are others): Sesame Street (see http://www.sesamestreet.org/) and Headstart (see https:// www.acf.hhs.gov/ohs/about/history-of-head-start).

Perhaps an educational technology project should be based on whether or not there are subsequent projects building on the findings of earlier works. In that sense, Jasper Woodbury (see https://jasper.vueinnovations.com/) was successful as it eventually led to such efforts as Marcia Linn's WISE (see https://wise.berkeley.edu/). One could argue likewise for the success of Seymour Papert's Logo (see http://el.media.mit. edu/logo-foundation/what_is_logo/history.html), which eventually led to Scratch and Co-Lab (see https://www. media.mit.edu/people/mres/projects/). However, none of those efforts resulted in large-scale, sustained adoption in 
American classrooms although they demonstrated positive outcomes, as have other innovative works.

The point that I have been making in recent years concerns a failure to connect theory and research with practice, policy and the management of educational systems - that is the purpose of the major online reference work entitled "Learning, Design and Technology: An International Compendium of Theory, Research, Practice and Policy" (see http://link.springer.com/ referencework/10.1007\%2F978-3-319-17727-4). Based on past experience, I am not optimistic that this effort with that work will have the intended impact. What typically happens is that researchers talk to other researchers, school administrators listen to vendors and selected teachers, and teachers form their own small communities of practice with limited access to research on various educational technologies.

Perhaps it is time for those in our profession to stop overpromising and to realize the challenges in turning good research into practice that lives well beyond specific studies and experiments. Consider the following guiding mantras for adoption by educational technology researchers and advocates:

- It is not about the technology - it is about the learning.

- It is not about the technology - it is about the use of the technology.

- It is not what one says that matters - what matters is what one does (Gagné said that our job is to help people learn he said that to researchers at AERA who were asking about publishing their research results).

- What matters is the will of a society to value and support education - this is the most fundamental challenge in the USA.

There are no doubt successful research projects in the sense that they demonstrate some of their intended outcomes. What has yet to occur is the translation of those outcomes into sustained practice on a large scale in this country. For example, I do believe the UVA-Smithsonian STEAM effort (see https://news.virginia.edu/content/smithsonian-curry-givestudents-chance-reinvent-famous-creations) will have a positive impact. It is not clear that school districts will change curricula or invest in innovation and teacher support in the way that those at BNDS have been doing since 1952 .

After the meeting, I recalled my experience in Indonesia with multi-grade rural schools - it led to a dissertation studying 12 such schools. I visited a rural school in the Bogor District that took two hours by car to reach a village and then another hour or so walking for two miles to reach the school that served three somewhat remote mountain villages. It was a three-room schoolhouse with no computers, electricity wired outside buildings, one blackboard and chalk in each room - one room for 1st and 2nd grade, one for 3rd and 4th grade, and one for 5th and 6 th grade students. There were about 50 children in each of those rooms, three to a desk sharing one pencil, one pad of paper and a straight edge. I observed the 5th and 6th grade classroom. The teacher only had a two-year college degree, but was also going full-time to get his baccalaureate as had been mandated by an Indonesian law. He was amazing in the classroom. The 5th grade students were studying math - geometry to be more specific. The 6 th grade students were studying science - botany in that lesson. When the teacher looked at the left side of the room (5th graders), the 6th graders worked quietly on a problem. When he shifted to look at the other side, the 5 th graders worked quietly. After an hour or so, the 6th graders all got up and left the classroom. The teacher then showed the 5 th grade students how to calculate the perimeter of a polygon, constructed with a right triangle on top of a rectangle. To solve the problem, the students had to know the Pythagorean theorem - 5th grade students in a rural, multi-grade school in Indonesia knew the Pythagorean theorem. I was riveted. After working two examples on the board, the teacher set the students to working a problem on their own in the groups of three to a Table. I watched each group work together to solve the problem - no fighting over the one pencil or straight edge and they understood the Pythagorean theorem and used it to correctly solve the problem.

Then, I began to wonder what happened to the 6th grade students. My Indonesian colleague told me that they had been sent outside to find plants that could reproduce without seeding - e.g., by plant cloning. I went outside to observe. What I saw were small groups of students (3 to 5), sharing one knife, finding plants and cloning them - all without adult supervision. I was again amazed.

At the end of the day, the parents came up from the fields to greet us and exchange ideas. They wanted to know how to improve the school and the teaching - we had nothing to offer. Nothing. We then asked them what their goals were. Through a translator, we were told they wanted their children to get a high school education - that meant the children would have to leave the village and spend the week or year in Bogor (two hours away by bus). We asked how many now go on to high school. The answer, about 10\%. We asked what happens to them? The response is that they find jobs in the city. We enquired about their goals for these children? The goal is for $75 \%$ to go on to high school. What happens to the village if they do not return? Shrugs are given in reply. These parents valued the education of their children more than the survival of their villages. Given that amazing experience, we wanted to see if it held up in other situations, so we had Florida State University doctoral student visit and study 12 other schools. I visited several of them with her and saw the same kind of commitment to education in other rural multi-grade schools in Indonesia.

The challenges education faces in Indonesia are arguably more formidable than those we face in the USA, but I am inclined to believe the will of the people to educate their children will play a greater role than almost anything else - technology or otherwise. That is why I am optimistic, and realistic at the same time. 